\section{Ambulatory care of paediatric and adolescent diabetic patients in the Western Cape}

To the Editor: It has been proposed that routine care of paediatric and adolescent patients with type 1 diabetes (T1DM) in the Western Cape should be devolved from centres of excellence to centres at secondary or even primary level. Experience with adults with type 2 diabetes (T2DM) in another African country is cited to support this notion. ${ }^{1}$ However, these two conditions have completely different aetiologies. While T2DM is entirely preventable and treatable by simple measures, this is not the case with T1DM. T1DM usually starts in childhood, and children can by no means be considered 'little adults'. They vary in size, growth phase and pubertal stage. Their manipulative skills can catch many a health worker off-guard. Maintaining optimal blood glucose control in order to prevent both acute (diabetic ketoacidosis and hypoglycaemia) as well as chronic (microvascular and macrovascular) complications is therefore far more difficult in this age group than in any other. The International Society for Paediatric and Adolescent Diabetes (ISPAD) in the latest Clinical Practice Consensus Guideline (supported by delegates from Africa) therefore recommends that children and adolescents with diabetes 'should be cared for ... by members of a team of specialists, all of whom should have training, expertise, and understanding of both diabetes and paediatrics, including child and adolescent development.' ${ }^{2}$ Such a team would consist of a paediatric endocrinologist or an experienced paediatrician, a diabetic nurse educator, a dietician, a social worker, a psychologist and an ophthalmologist.

Randomised controlled trials in children with T1DM to support ISPAD's recommendation are not available, and for ethical reasons may never be done. In certain African countries where there are no or few paediatric endocrinologists or diabetologists, children with T1DM have a shortened life expectancy (0.96 years in Mali, 3.5 years in Mozambique, 11.2 years in Zambia). ${ }^{3}$ This suggests that lack of expertise is indeed associated with significant mortality among diabetic patients. In adult ambulatory diabetic care, adherence, monitoring of blood sugar and detection of complications is significantly better when patients are looked after by endocrinologists as opposed to generalists. ${ }^{4}$ These patients usually also have a better $\mathrm{HbA}_{1 \mathrm{c}}$ level, and significantly fewer develop end-stage renal disease. Furthermore, a multidisciplinary diabetes management team has been shown to impact on the cost of diabetic keto-acidosis, duration of hospital stay, number of emergency room visits and hospitalisations, hypoglycaemia and foot infections. ${ }^{4}$

Given the above, a secondary hospital geographically distant from a centre of excellence should only consider duplicating a diabetic ambulatory service if a multidisciplinary diabetes management team is available. An appropriately stocked dispensary, run by a motivated pharmacist, is also essential to prevent some of the problems frequently encountered at primary care centres. ${ }^{5}$ If these requirements cannot be met, it would not be in the interests of children and adolescents with T1DM to devolve their care to secondary or primary level.

\section{Ekkehard Zöllner \\ Paediatric Endocrine Unit \\ Tygerberg Children's Hospital \\ W Cape \\ zollner@sun.ac.za}

\section{Steve Delport}

Paediatric Endocrine Unit

University of Cape Town
Bahendeka S. The provision of hospital-based glucose monitoring and structured clinical files improves metabolic control of diabetics in rural areas of Uganda. Diabet Med 2006;23(P1709):603 (abstract). 2. Pihoker C, Forsander G, Wolfsdorf J, Klingensmith GJ. The delivery of ambulatory diabetes care:
structures, processes, and outcomes of ambulatory diabetes care. Pediatr Diabetes 2008;9:609-620. Beran D, Yudkin J, DeCourten M. Access to insulin and diabetes care in Mali, Mozambique and Zambia

and differences in life-expectancy. Diabet Med 2006;23(P1722):603 (abstract).
Cobin RH. Subspecialist care improves diabetes outcomes. Diabetes Care 2002;25:1654-1656.

4. Cobin RH. Subspecialist care improves diabetes outcomes. Diabetes Care 2002;25:1654-1656.
5. Haque M, Emerson SH, Dennison CR, Navsa M, Levitt NS. Barriers to initiating insulin therapy in Haque M, Emerson SH, Dennison CR, Navsa M, Levitt NS. Barriers to initiating insulin therapy in
patients with type 2 diabetes mellitus in public-sector primary health care centres in Cape Town. S Afr Med J 2005;95:798-802.

\section{Termination of pregnancy and children}

To the Editor: Recent articles ${ }^{1,2}$ addressed the duty of health care professionals and researchers to report sexual activity involving children. They discuss the interpretation and practical implications of section 54 of the Criminal Law (Sexual Offences and Related Matters) Amendment Act No. 32 of 2007 (Sexual Offences Act), which requires that 'a person who has knowledge that a sexual offence has been committed against a child must immediately report such knowledge to a police official. The articles give guidance on the circumstances under which health care professionals and researchers, respectively, should report child abuse and who to report it to. However, it is of concern that some of their arguments seem to be based on a misinterpretation of section 56(2) of the Sexual Offences Act.

McQuoid-Mason ${ }^{1}$ highlights inter alia the conflict between medical confidentiality and the mandatory reporting of consensual sexual acts with certain children which is criminalised under the Sexual Offences Act (sections 15, 16). He suggests that it may be justifiable for a medical practitioner not to report a pregnancy of a child resulting from a statutory rape (i.e. consensual sexual penetration) in cases where the defence of section 56(2)(b) of the Sexual Offences Act is applicable. Under section 56(2)(b) of the Sexual Offences Act it is a valid defence 'to contend that both the accused persons were children and the age difference between them was not more than two years at the time of the alleged commission of the offence. His argument seems to be that if the court would not find the children guilty of statutory rape because of a valid defence, then there is no basis for asking the medical practitioner to report such an offence (and breach his patient's confidentiality) in the first place. However, the defence of section 56(2)(b) of the Sexual Offences Act does not apply to statutory rape; it only applies to the offence of statutory sexual assault (section 16 of the Sexual Offences Act), which deals with non-penetrative sexual acts with certain children. The argument of section 56(2)(b) of the Sexual Offences Act serving as a defence for statutory rape and thereby obliterating the doctor's duty to report is therefore of no avail.

Similar thoughts seem to guide Bhana et al. ${ }^{2}$ in discussing standards for researchers for the reporting of sexual activity and abuse of minors. They argue that no formal reporting action needs to be taken by researchers when receiving reports of consensual sex between minors where the parties involved are no more than 2 years apart in age. They emphasise that the age difference of 2 years is a crucial factor for a decision about reporting sexual activity. However, in the light of section 56(2)(b) of the Sexual Offences Act, the age difference can only be a guide in deciding about reporting cases of consensual sexual violation with children (i.e. non-penetrative sex), because the provision does not apply to statutory rape.

The authors' suggestion that the Sexual Offences Act 'replaces previous legislation where reporting could be done to a social worker or the police' ignores the fact that the Sexual Offences Act does not repeal or amend the mandatory reporting provisions created under 
the Children's Act No. 38 of 2005. Reporting sexual child abuse to the Department of Social Development, a designated Child Protection Organisation or the police, as provided for under section 110(1) of the Children's Act, is therefore still an option.

We recognise the urgent need to provide guidance and specific protocols to clarify health care professionals' and researchers' duties when working with children. However, these must be carefully drafted to truly comply with existing legislation.

\section{Stefanie Röhrs}

Gender Health and Justice Research Unit

University of Cape Town

stefanie.rohrs@uct.ac.za

1. McQuoid-Mason D. Termination of pregnancy and children: Consent and confidentiality issues. S Afr Med J 2010;100:213-214

2. Bhana A, Swartz S, Davids A. Standards for the reporting of sex/sexual activity of minors in a research context. S Afr Med I 2010;100:642,644.

Professor McQuoid-Mason replies: Dr Röhrs states that the suggestions made in the $S A M J^{1,2}$ are not a true reflection of the law in the Sexual Offences Act. ${ }^{3}$ She correctly points out that it is only in respect of statutory sexual assault and not statutory rape that the Sexual Offences Act ${ }^{4}$ states that it is a defence that both the accused were children under the age of 16 years and the age difference between them was not more than 2 years at the time of the alleged offence. She further states that reporting sexual child abuse in terms of the Children's Act ${ }^{5}$ is still an option. I submit that there are still good reasons why doctors may be able to avoid criminal liability in terms of the Sexual Offences Act ${ }^{3}$ for not reporting such cases where it would not be in the best interests of the children to do so.

The constitutional principle of the best interests of the child must prevail over the duty under the Sexual Offences Act to report consensual sexual penetration between children under 16 years where their age difference is less than 2 years.

The Constitution, ${ }^{6}$ the supreme law of South Africa, ${ }^{7}$ clearly states: 'A child's best interests are of paramount importance in every matter concerning the child. ${ }^{6}$ The Constitution does not define the child's 'best interests', but the Children's Act states that factors that should be taken into account are: (i) the nature of the relationship between 'the child and any other care-giver or person relevant in those circumstances'; (ii) the child's age, maturity and stage of development, gender, background and any other relevant characteristic of the child; (iii) the child's physical and emotional security and his or her intellectual, emotional, social and cultural development; (iv) the need to protect the child from any physical or psychological harm that may be caused by subjecting the child to maltreatment, abuse, neglect, exploitation or degradation or exposing the child to violence or exploitation or other harmful behaviour; and $(v)$ deciding which action would avoid or minimise further legal or administrative proceedings in relation to the child.

Requiring doctors to report to the authorities consensual sexual penetration between adolescents where both are children under the age of 16 years and the age difference between them is not more than 2 years, violates most of the factors in the Children's Act ${ }^{8}$ as affecting the best interests of the child standard, and may be considered unconstitutional. For instance, the best interests of the child will be undermined if a report in terms of the Sexual Offences $\mathrm{Act}^{4}$ results in criminal prosecution because: $(i)$ the relationship between doctors and the children concerned may be harmed where such doctors are 'relevant persons' regarding terminations of the pregnancy, and girl children will no longer trust or seek help from them; (ii) the Act does not allow a doctor a discretion to take into account the children's age, maturity and stage of development, gender, background and any other relevant characteristics; (iii) the children's physical and emotional security may be harmed and their intellectual, emotional, social and cultural development adversely affected if they are exposed to the criminal justice system; (iv) the children may suffer physical or psychological harm by being exposed to degradation or other harmful behaviour when interrogated by the police or others in the criminal justice system; and $(v)$ a criminal charge will expose the children to legal or administrative proceedings, which the Children's Act ${ }^{8}$ states should be avoided. Despite the criminalisation of the duty to report consensual sexual penetration between adolescents where both are children under the age of 16 years, and the age difference between them is not more than 2 years at the time of the alleged offence, doctors may avoid making such a report where they are acting in the best interests of the child' as required by the Constitution (for a full discussion for the rationale behind these submissions, see McQuoid-Mason').

\section{Should consensual penetrative sex between teenagers} less than 16 years old who have an age difference of less than 2 years be reportable as 'child abuse' in terms of Children's Amendment Act?

'Child abuse' may be defined as 'maltreatment of children which results in harm or the potential risk of harm to a child, usually of a physical, emotional or sexual nature. ${ }^{10}$ The Children's Amendment $\mathrm{Act}^{11}$ imposes a legal duty on individuals and health care professionals who on reasonable grounds conclude that a child has been physically injured, sexually abused or deliberately neglected. ${ }^{12}$

The reporting person must have reasonable grounds for concluding that the child has been physically or sexually abused or deliberately neglected and needs care and protection. Therefore, if the doctor concerned does not conclude that child abuse has occurred, such conduct does not have to be reported in terms of the Children's Act $^{12}$ - provided the doctor is acting in the best interests of the child as required by the Constitution ${ }^{6}$ and the Children's Act. ${ }^{13}$ Where the age difference between the children engaged in consensual sex is less than 2 years, whether or not the doctor reports this to the authorities in terms of the Sexual Offences Act ${ }^{4}$ will depend on the best interests of the children, as required by the Constitution. ${ }^{6}$

It may also be argued that where the age difference between the children is less than 2 years and consensual sex has occurred, such conduct does not constitute child sexual abuse and should not be criminalised - unless one of the children was in a position of power or control over the other - as is the case in Canada. ${ }^{14}$

\footnotetext{
1. McQuoid-Mason D. Termination of pregnancy and children: Consent and confidentiality issues. S.Afr Med J 2010;100:213-214

Bhana A, Swartz S, Davids A. Standards for the reporting of sex/sexual activity of minors in a research context. S.Afr Med J 2010;100:642,644.

Section 56(2)(a) of the Criminal Law (Sexual Offences and Related Matters) Amendment Act No. 32 Section 56(2)(a) of the Criminal Law (Sexual Offences
of 2007.

Section 110(1) of the Children's Act No. 38 of 2005.

Section 28(2) of the Constitution of the Republic of South Africa of 1996

Section 2 of the Constitution of the Republic of South Africa of 1996.

8. Section 7(1) of the Children's Act No. 38 of 2005.

9. McQuoid-Mason DJ. Mandatory reporting of sexual abuse under the Sexual Offences Act and the best interests of the child. South African Journal of Bioethics and Law 2011 (in press). McQuoid-Mason D, Dada M. A-Z of Nursing Law. Cape Town: Juta \& Company, 2009:45.

11. Children's Amendment Act No. 41 of 2007.

12. Section 110 of the Children's Act No. 38 of 2005, as amended by the Children's Amendment Act No. 41 of 2007.

Section 9 of the Children's Act 38 of 2005 .

14. Section 150.1(2)(a) of the Canadian Criminal Code RSC.1985, c.C-46.
} 